\title{
THE IDENTIFICATION OF TECHNOLOGY PLATFORMS AND INNOVATION AREAS WITH HIGH REGIONAL IMPACT
}

\author{
NATAŠA URBANČÍKOVÁ
}

\section{INTRODUCTION}

The important role of $R \& D$ and innovation in EU were in high interest of the Lisbon and Barcelona European councils. The European Union set several main goals for the further EU enhancement and competiveness. One of them was to raise overall research investment in the EU from $1.9 \%$ of GDP to approaching $3 \%$ by 2010. European Council in March 2005 re launch the Lisbon strategy with main strategic message: growth and jobs. One of three main areas of action in the new Lisbon partnership for growth and jobs became knowledge and information. Research and innovation were put in the heart of the EU policies, EU funding and business. In connection with these strategic decisions the high potentials started to play irreplaceable role of EU policy.

\section{HUMAN CAPITAL AND HIGH POTENTIALS IN THE REGIONAL INNOVATION PROCESS}

An increasing interest has emerged both in theory and policy, which focuses on the importance of knowledge, learning and innovation to the economic success of firms, regions and nation-states (Lundvall, 1988; Forrant, 2001). New theories emphasise the role of human and social capital in regional growth and development as missing elements of its explanation. Regional strategic planning and decision-making suppose high quality of human capital and the involvement of regional authorities, research entities and business community in national and European initiatives to mobilise to facilitate actions.

Innovation takes a central role in the process of economic development, when defining it as a product, process and organisational innovation in the firm as well as social and institutional innovation at the level of industry, region or nation. Since economic development can be understood as a process of innovation activities, innovation emerges as the engine of growth and the role of institutions is an essential variable, "the national innovation system became an important part of national industrial policies" (Lundvall, 1988). As the conditions of regions in the regionalisation process are gradually changing over the time, what brings - in accordance with learning regions concept - new challenges such as change of the 
regional governance system toward more networking structure, embedding together cooperation and competition, away from hierarchical structures. Regionalisation accompanied by decentralization of power and resources leads to a situation when regional (innovation) policies started to play more important role.

An important input for the discussion comes from the regional innovation systems (RIS) approach, which accentuates the critical significance of geographical proximity and adequate institutional support of economy, entrepreneurship and innovation at the regional level. The concept of the regional innovation system appeared in the early 1990s, integrating two ideas: the systematic nature of innovation activity and the regional dimension of the innovation process. Its systematic approach is based on the specific nature of innovation activity, which results from cooperation among business entities based on mutual trust in creating, disseminating and applying new knowledge.

A strong, regional innovation system is one with systematic linkages between external as well as internal sources of knowledge production (universities, research institutions and other intermediary organisations providing innovative services) and firms (both large and small). Most regions do not have these systemic innovation characteristics (Cooke\&Memedovic, 2003).

The bigger companies of all sizes and industries are managing gradually more diverse workforces across a complex cultures, geographies, and economic environments. Human resources departments and organisations are challenged to identify, assess, develop, and retain high-performing and high-potential talents.

High potentials consistently and significantly outperform their peer groups in a variety of settings and circumstances. While achieving these superior levels of performance, they exhibit behaviours that reflect their companies' culture and values in an exemplary manner. Moreover they show a strong capacity to grow and succeed throughout their careers within an organisation - more quickly and effectively that their peer group do (Ready, Conger\&Hill, 2010). Additionally, the high potentials talents are defined as an employee who is assessed as having the ability, organisational commitment and motivation to rise to and success in more senior positions in the organisation.

The role of high potentials in regional growth and development is highly connected to regional innovation systems and vice versa, which were first mentioned in 1990's in the regions/or states and their key substances.

We may suppose that the assets in the innovation-based economic development model include human, intellectual, financial, physical, and institutional capital located in a region. Talented people construct new ideas driving innovation and regions are increasingly advertising strengths in skilled labour to attract and preserve innovative companies. Many studies of business location decisions have shown skilled labour to be such an important asset, that a lot of regions have made it the central topic of their regional marketing efforts. Indeed, the presence 
of high potentials is a basis for business attraction. Regional administration is not able to develop a skilled workforce without investment into the institutions that generate and cultivate talents such as universities and other educational and training institutions.

If a region is attractive for high potentials - highly skilled and talented human capital, the regional innovation activity becomes more dynamic leading to its economic growth and competitiveness increase, attracting in turn new highly skilled labour force. This means, a circle exists - the low proportion of highly skilled labour force makes the region less competitive. The less competitive region is not attractive for highly skilled labour force. When explaining innovation performance, human capital (read high potentials, inventors, etc.) is a key asset.

Networks among mentioned actors and establishing close cooperation with one another are solid bases to create technology innovation (Park\&Lee, 2003). Interactions between the actors in regional innovation system have been insufficiently explored, while the institutional context of these interactions has been to a large extent overlooked. As a result, the validity of the recommendations for innovation policy making based on the current analyses of regional innovation systems is somewhat questionable (Doloreux, D., 2003). Since regional innovation policies most of policy measures are focused on improving innovative capacity of SMEs (focal recipients of R\&D support), this indicates that SMEs are the core factor for a regional innovation system, while Schumpeter already in 1931 urged that "a driving force of economic growth is based on entrepreneurship“. The innovation system itself is not regarded as productive unless it creates new products in the domestic and global markets. Therefore a commercialisation process is very significant in order to link the innovation system to economic growth (Park\&Lee, 2004).

High potentials are intensively studied in the regional science and/or "new economic geography" (Krugman, 1991, Nobel prize winner in 2008). Economic geography includes characteristic patterns of successful regions; the existence of a strong SME sector, intensive horizontal work structure, a dense infrastructure of supportive institutions and organisations, and innovative regional culture and an active regional government (Zeitlin 1992, Pyke and Sengenberger 1992).

Regional development is essentially based on human capital assets, as a necessary precondition. Small and medium enterprises are in a less favoured situation, fighting for good quality graduates with large companies. As one of the key measures to strengthen the high potentials acquisition, training in SMEs is promoting and assisting the SMEs in their innovation, research and development activities via creation of well functioning, regional SMEs tailored regional innovation system. 


\section{METHODOLOGY}

The IDEA project involves 8 regions within Central Europe at NUTS III level as follows:

1. Chemnitz, Kreisfreie Stadt in Germany

2. Gorenjska in Slovenia

3. Košický kraj in Slovakia

4. Fejer in Hungary

5. Alessandria in Italy

6. Miasto Lodz in Poland

7. Ustecký kraj in Czech Republic

8. Eastern upper Styria in Austria

All regions have been analysed with the aim to find out the most innovative fields and sectors of innovation in the different regions. The task was to choose fields and sectors of innovation which:

- are in line with regional priorities;

- are in line with the European priorities;

- show a positive development in the last years;

- cooperate with other fields or sectors of innovation, cluster or technology platforms.

The four areas have been identified for data gathering. Those areas are:

- Technology platforms, to go in line with European priorities;

- Cluster, to go in line with regional priorities;

- Fields of innovation, concentration on the companies of a region;

- Sectors of innovation, concentration on universities, schools, R\&D departments of a region.

In a first step the selection procedure has been carried out. The important clusters and technology platforms for the region have been evaluated. Also the fields and sectors of innovation were settled down in a region. In the second step the selected business and research indicators have been collected based on the fields and sectors which had been chosen in the first step. The data has been evaluated not only for one year but for 5 years in order to see the development of the different fields and sectors of innovation.

After the evaluation of the cluster, technology platforms, fields and sectors of innovation the cooperation's and connections among them has been researched. This ensured a wide range of skills which makes the decision in the last step easier. After the decision of the fields and sectors of innovation the chosen fields and sectors of the region have been described and the reasons for their choice have been explained.

The process of the future fields of technological has been prepared. The first of all the combination of identified fields and sectors of innovation has been investigated. Two summaries have been prepared. The first one regarding the 
combination of sectors and fields based on the identified fields of innovation and another one based on the identified sectors of innovation. Subsequently the decision about 10 future fields of technological innovation has been done.

The statistical units of innovation surveys can be broken down according to different classifications. The most important classification is the principal economic activity of the statistical unit. The International Standard Industrial Classification (ISIC Rev.4) and the statistical classification of economic activities in the European Community (NACE Rev.2) are appropriate international classifications for this purpose. The Figure 1 shows the combination of the chosen fields and sectors of innovation on the basis of fields of innovation for selected 8 regions.
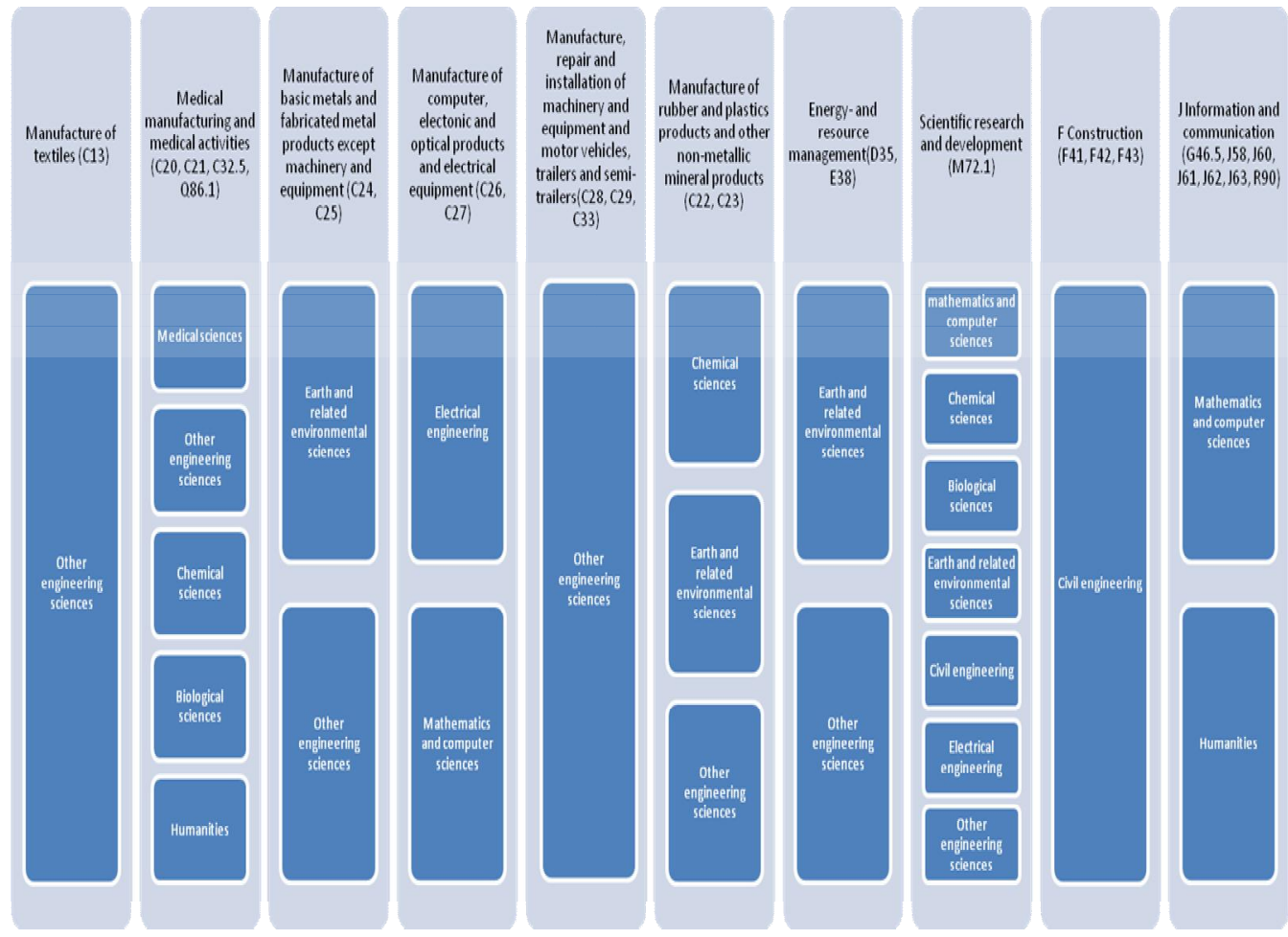

\section{Economics}

Figure 1-Combination of the chosen fields and sectors of innovation on the basis of fields of innovation (Faber, Ch. , 2011)

\section{RESULTS}

The many fields and sectors of innovation have been selected based on methodology stated above. As for the IDEA project purposes there was not possible to deals with all of them, the method for mutual relationship between the sectors and the fields of innovation has to be found out. It leaded to 10 future 
fields of technological innovation definition. Two alternatives have been developed, the combination of sectors and fields based on the fields of innovation and the combination of sectors and fields based on the sectors of innovation. Finally the defined future fields based on the fields of innovation in connection to the sectors of innovation has been chosen as a common basis for the further approach within the project IDEA.

The researched region stated the different reasons for sectors and fields of innovation selection. In Chemnitz region, Germany the chosen fields of innovation were Manufacture of textiles, Manufacture of computer, electronics and optical products, Manufacture of electrical equipment, Manufacture of machinery and equipment n.e.c., Manufacture of motor vehicles, trailers and semi-trailers. The chosen sectors of innovation were Natural sciences, Humanities and Social sciences. The reason was that the most of the companies are settled down in selected fields of innovation. There is also cooperation between the identified sectors of innovation and the identified fields of innovation.

The Gorenjska, Slovenia had chosen the Automotive cluster and Technology network of information and communication technologies because the Automotive cluster (61 members) and the technology network of information and communication technologies (52 members) are both one of the largest and strongest cluster in Slovenia. Both have an international partnership network and offer a large range of services to their members and also cooperate with DAs'. They are a member of several international technology platforms and are constantly upgrading and updating its services, expertise and broaden international market for its members.

Košický kraj in Slovakia based their decision mostly on regional priorities, European priorities, sectors of innovation which show a positive development in the last years and sectors of innovation which cooperate with other fields or sectors of innovation, clusters or technology platforms. The fields were selected in the area of Civil, mechanical and electrical engineering (Manufacture of other non-metallic mineral products, Manufacture of basic metals, Manufacture of computer, electronic and optical products, Manufacture of electrical equipment, Manufacture of machinery and equipment n.e.c., Manufacture of motor vehicles, trailers and semi-trailers, Electricity, gas, steam and air conditioning supply, Water supply; sewerage; waste management and remediation activities, Construction), area of Information and communication technologies (Wholesale of information and communication equipment, Publishing activities, Programming and broadcasting activities, Telecommunications, Computer programming, consultancy and related activities, Information service activities, Creative, arts and entertainment activities) and in the area of Natural and life sciences (Manufacture of chemicals and chemical products, Manufacture of basic pharmaceutical products and pharmaceutical preparations, Manufacture of medical and dental instruments and supplies, Research and experimental development on natural sciences and engineering, Hospital activities). 
Fejer in Hungary selected fields of innovation in Manufacture of motor vehicle, trailers and semi-trailers and other manufacturing, Electricity, gas, steam and air conditioning supply and Waste collection, treatment and disposal activities, materials recovery. The chosen sectors of innovation are Mathematics and computer sciences, Chemical sciences and Other engineering sciences. The results were supported by the Regional Innovation Strategy, Regional Operational Programme and Regional Action Fields and gave the opportunity to highlight the core branches of the region which are Materials and Technology, Information and Communication technologies, Mechatronics, Automobile Industry, Logistics, Green technology and Food manufacturing.

Region Alessandria in Italy considers as the most important fields and sectors of innovation in Alessandria economy the ones where more firms exist and which are more industrialized. They are the ones related to packaging and plastic material district (214 firms), to which it is possible to add the firms of the packaging and logistic district (29 units) and the ones related to the transport and logistics district (151 firms). The field of innovations are Chemical sciences, the other engineering sciences and the earth and related environmental sciences. These fields of innovation have been chosen because Alessandria economy is strictly interconnected and there is a high cooperation with the other regional clusters.

Miasto Lodz in Poland had chosen the sectors of innovation Computer sciences and Biological sciences and fields of innovation Computer programming, consultancy and related activities, Manufacture of chemicals and chemical products, Manufacture of basic pharmaceutical products and pharmaceutical preparations. The chosen fields and sectors of innovation are in line with priorities of Lodz defined in long mid-term development strategy, which focus on i.a. developing business services sectors and IT sector. Both sectors have shown a positive development in the last years in terms of start-ups and the level of employment. They are consistent with the European priorities.

In the region of Eastern upper Styria in Austria the sectors of innovation have been selected as Natural sciences, Engineering and technology and Economics. The Chosen fields of innovation are Manufacture of rubber and plastics products, Manufacture of basic metals, Manufacture of fabricated metal products, except machinery and equipment, Manufacture of machinery and equipment n.e.c. The reason is that especially the industrial and commercial sectors are above average importance. The economic focus of the region is in the range of materials (steel, stainless steel, metals, and plastics). In this sector the real strengths of the region are concentrated and international competitiveness is demonstrated here continuously. To ensure this in the future it will require well-trained staff. The region of eastern upper Styria is captured by a demographic change therefore, measures are essential to ensure the supply of quality workers. Furthermore, the economic structure of the eastern upper Styria is markedly different from the economic structure in Austria. In the eastern upper Styria region, particularly the 
secondary sector is very dominant while the share of agriculture and forestry and of the service sector is below the value of Austria.

The Ustecky kraj in Czech Republic had identified fields of innovation as Manufacture of rubber and plastics products and Repair and installation of machinery and equipment and sectors of innovation as Engineering sciences and Biological sciences.

The reason is that the Manufacture of rubber and plastics is an important part of the industrial structure of the Usti region. It is a constantly developing sector using modern technologies, as well as research and development results. Repair and installation of machinery and equipment is an important part of the industrial structure of the Usti region. Given that the mining, energy and chemical industry and mechanical engineering are the main sectors in the region, is the field with a future. It develops constantly, uses modern technologies, as well as research and development results. Engineering sciences is typical for Usti region and due to its industrial character is very important. Innovative field is focused on production technology, material engineering and surface engineering, especially in machine building. High potential from these sectors is scarce and demanded in the region. Like engineering sciences, Biological sciences including environmental issues are typical and important for Usti region due its industrial character. They are focused on research of areas with heavy drain environment and population in interaction with health of the population and other natural and socio-economic implications and in research of areas with different degrees of environmental protection and prevention of environmental degradation.

Based on the country research the following field of innovation have been chosen:

a) Based on sectors of innovation

- Mathematics and computer sciences (Information and communication)

- Chemical sciences

- Earth and related environmental sciences

- Biological sciences

- Civil engineering

- Electrical engineering

- Other engineering sciences

- Medical sciences

- Economics

- Humanities

b) Based on fields of innovation

- Manufacture of textiles

- Medical manufacturing and medical activities

- Manufacture of basic metals and fabricated metal products except machinery and equipment 
- Manufacture of computer, electronic and optical products and electrical equipment

- Manufacture, repair and installation of machinery and equipment and motor vehicles, trailers and semi-trailers

- Manufacture of rubber and plastics products and other non-metallic mineral products

- Energy and resource management

- Scientific research and development

- Construction

- Information and communication

Based on the process of decision two concepts how to combine the chosen sectors and fields of innovation to come to 10 future fields of technological innovation having high qualitative and quantitative demand of high potentials have been defined.

The consortium of the project partners decided together to use the defined future fields based on the mentioned fields of innovation in connection to the mentioned sectors of innovation as a common basis for the further approach within the project IDEA.

\section{CONCLUSION}

Regional development is essentially based on human capital assets, as a necessary precondition. Small and medium enterprises are in a less favoured situation, fighting for good quality graduates with large companies. As one of the key measures to strengthen the high potentials acquisition, training in SMEs is promoting and assisting the SMEs in their innovation, research and development activities via creation of well functioning, regional SMEs tailored regional innovation system. In order to prepare the tailored made strategies for high potentials the selection of future field of innovation is necessary as a precondition for strategy that meets real needs of the regions.

\section{REFERENCES}

Cooke, P., Memedovič, O. (2003), Strategies for regional innovation systems; Learning transfer and applications; Centre for advanced Studies, Cardiff University and Unido Strategic Research and Economic Branch, UNIDO, Vienna

Doloreux, D. (2003), Regional innovation systems; A critical rewiew; Chaire de rechercu du Canada en developpmetn regional, Universite du Quebec a Rimouski, Saeed Parto, Maastricht Economic research Institute for innovation and Technology (MERIT), University of Maastricht

Farber, Ch. (2011), Identification of technology platforms and innovation areas with high regional impact, Internal report of IDEA project 
Forrant, R. ( 2001), Pulling Together in Lowell: The University and the Regional Development Process, European Planning Studies, Vol. 9, No. 5, pp. 613 - 628.

Krugman P. (1991), Geography and Trade, Cambridge, MA, MIT Press

Lundvall, B.-Å.(1998), 'Why study national systems and national styles of innovation?', in Technology Analysis \& Strategic Management, Vol. 10, No. 4, pp.407-422.

Park, S. Ch., Lee, S.K. (2003), The regional innovation system in Sweden; a study of regional clusters for the development of high technology; Springer Verlag London Limited

Park, S. Ch., Lee, S.K. (2004), The national and regional innovation system in Finland; from the path dependency to the path creation approach; Springer Verlag London Limited

Pyke, F., W. Sengeberger, eds. (1992), Industrial Districts and local economic regeneration, Geneva, International institute for Labour studies

Schumpeter, J.A (1931), Theorie der Wirtschaftlinchen Entwicklung, Duncke\&Humblot, Munich

Ready D.A., Conger, J.A., Hill, L.A. (2011), Are You a High Potential? Available from: www.hbr.org/2010/06/are-you a high-potential/ar/1, Accessed: August, 2011

Zeitlin, J. (1992), Industrial districts and local economic regeneration; overview and comments in F. Pyke and W. Sengenberger(eds) Industrial districts and local economic regeneartion, Geneva: International institute for Labour studies

\footnotetext{
ABOUT THE AUTHOR

Assoc. Prof. Nataša Urbančíková, PhD.

Faculty of Economics, Technical University of Košice, Slovakia

e-mail: natasa.urbancikova@tuke.sk
} 